\title{
Linearity investigation from a vibratory fatigue bench
}

\author{
Christophe Gautrelet $^{1, *}$, Leila Khalij ${ }^{1}$, Aymeric Appert ${ }^{1}$, and Roger Serra ${ }^{2}$ \\ 1 Normandie Université, LMN/INSA Rouen Normandie, France \\ ${ }^{2}$ INSA Centre Val de Loire, UT, UO, Laboratoire de Mécanique G. Lamé, France
}

Received: 15 May 2018 / Accepted: 24 November 2018

\begin{abstract}
High-cycle fatigue behaviour of structures can be obtained through vibratory tests using frequency response functions or transmissibilities. To this end, this study deals with the qualification of the vibratory fatigue bench developed at the Laboratory of Mechanic of Normandy. This bench uses an electrodynamic shaker which can reach excitation frequencies that are higher than conventional fatigue machines. To carry out relevant tests, the capacities of the test bench must be well known. Correlations between excitation and response were investigated to determine the allowable setpoints to maintain linearity between the input and output signals to validate our system. The difficulties related to the experiments were presented and discussed.
\end{abstract}

Keywords: Vibratory fatigue test/ instrumentation/ vibratory bench capability/ linearity of the system

\section{Introduction}

In many industrial designs (automotive, aviation, etc.), it is necessary to predict fatigue strength and correctly improve reliability to ensure structures are safe. Traditionally, material fatigue tests are performed on servo-hydraulic machines whose cycle frequencies can range from few hertz to $1 \mathrm{kHz}[1,2]$ on the most recent models. Thus, tests using high-cycle fatigue to reach the endurance limit are costly in both time and material. Other equipments have been developed in order to create a greater number of cycles in a short time and to study the dynamic response of the structures, such as electrodynamic exciters, vibrophores, etc. Stanzl-Tschegg have described these different test methods in reference [3]. In 2004, George et al. gave a brief historical overview of these test benches [4]. The acceleration of vibratory fatigue tests with electrodynamic shakers has become more and more common in recent years $[5,6]$. These controlled closed-loop vibratory fatigue systems [7,8] can be used at relatively high frequencies $(>1 \mathrm{kHz})$ and therefore reduce the duration of the tests. The advantage of these benches is the possibility of exciting the structure close to the resonance without playing on the fatigue properties of the materials, unlike the vibrophores. The amplification due to the resonance allows to increase the strain levels (and consequently the stress levels) even if the input excitation level is relatively low, which implies a reduction in energy cost. More recently, different

\footnotetext{
* e-mail: christophe.gautrelet@insa-rouen.fr
}

experimental studies of vibratory fatigue damage with complex excitations have been developed in the literature (for example, we can quote the Ref. [9]) to better predict fatigue behaviour close to the actual service life. We can find in the literature a certain number of recent studies oriented towards vibratory fatigue. Some of them were concerned with structure design under random excitations [10-13] and multiaxial fatigue [14-17]. Others had established SN curves [18-20] or yet damage detection [21-26].

The Laboratory of Mechanic of Normandy (LMN) has set up a vibratory fatigue bench $[6,19]$ consisting of an electrodynamic shaker and a closed-loop control system that allows precise control. In order to set up complex tests (random, multiaxial, etc.) in the future, it is essential to know the behaviour of the bench according to the structure studied and the accessible excitation levels. The goal of this work was therefore to study the capability of the test bench from a linearity investigation between the excitation (amplitude of the imposed acceleration) and the response of the specimen (amplitude of the measured acceleration at the beam end and the related strain measured by a gauge) while highlighting the difficulties by carrying out such a test. The insufficiency of deterministic tests to represent the actual loads supported by a structure has been known for a long time [27], but this excitation type has allowed the qualification of our testing means. The experimental linearity of this bench should also lead to lighten the specimen instrumentation. Indeed, the added masses of the accelerometer at the beam end and the strain gauge bonding tend to disturb the measure structure response 


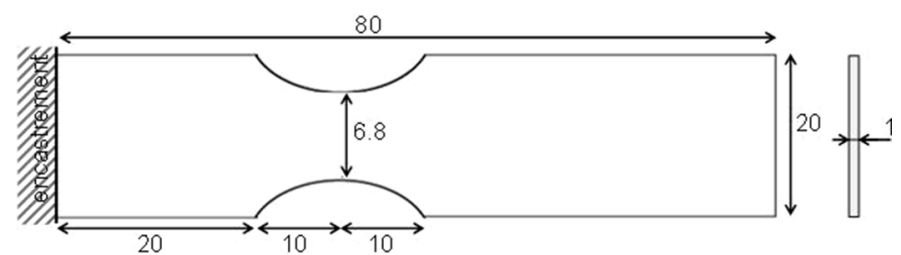

Fig. 1. Shape and dimensions of specimens (mm).

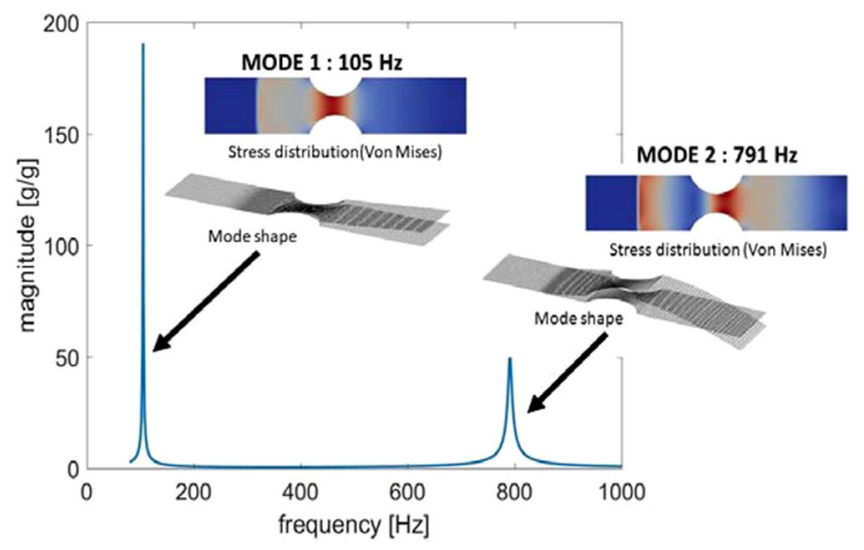

Fig. 2. Finite element analysis of the specimen.

by lowering its resonant frequency. In this way, we want to remove unnecessary response sensors (gauge or accelerometer).

The first part of this study gives details on the vibratory bench, the specimen and the experimental procedure, while the second part presents the results of the linearity tests for two amplifications, and the last part discusses the difficulties encountered in explaining the linearity zones defined by this study.

\section{The experimental procedure}

In this study, the low-carbon steel specimens were excited with sweep sines with the electrodynamic shaker. The test frequencies were fixed values obtained from the transmissibilities recorded between each test. A sinusoidal excitation level was then imposed at this frequency, increasing in increments from 1 to $20 \mathrm{~g}$. We have chosen to follow in this work the same approach as in reference [19]. An analysis of the experiments on a series of five samples was carried out in order to show the influence of the test frequencies.

\subsection{Specimen}

The dimensions of the tested specimen are described in Figure 1. The specimens were designed in order to define a stress raiser zone far from the clamp in order to fix the strain gauge and to have the first resonant frequency close to $100 \mathrm{~Hz}$ (see Fig. 2). The mode-I bending vibration leads to a higher deflection. Resonance modes are decoupled to limit any possible interaction.

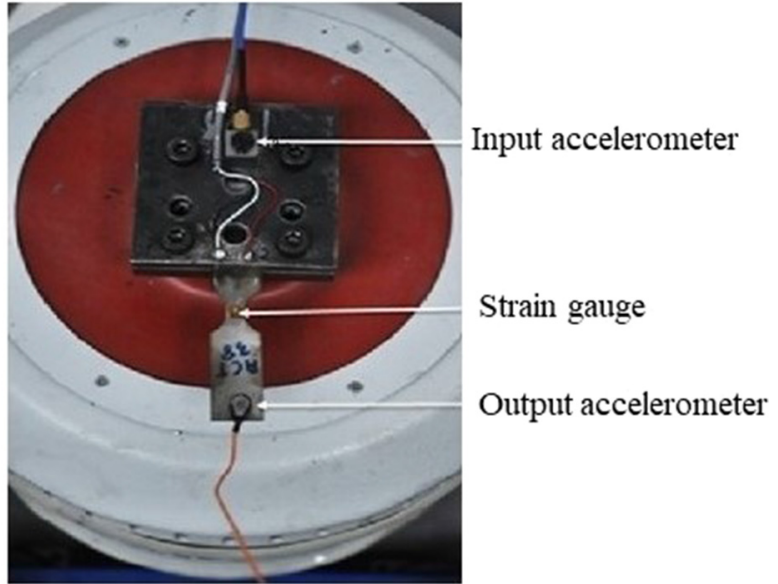

Input accelerometer

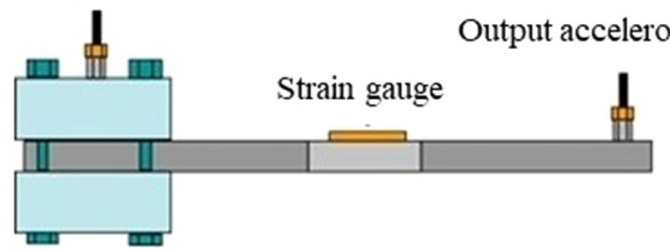

Fig. 3. Test bench and a schematic representation of the sensor positions.

The specimens were made with a low-carbon steel $(\% \mathrm{C}<0.1)$ material, with a yield stress of $235 \mathrm{MPa}$ and Young's modulus of $205 \mathrm{GPa}$. The series of five tested specimens underwent standard heat treatment $[28]\left(900^{\circ} \mathrm{C}\right.$ in a vacuum for $1 \mathrm{~h}$, followed by slow cooling in an air oven) to reduce the residual stresses in the specimen.

Note. Resonance frequency measurements may differ by a few tenths of hertz between one specimen and another due to the variability of machining.

\subsection{The vibratory fatigue bench}

The vibratory fatigue bench consists of an air-cooled electrodynamic shaker (TiraVib TV50100 + BAA1000+ FPS). An acquisition control system (ACP: Acquisition Control Peripheral of Spectral Dynamics) ensures the control of the tests. The power amplifier transforms the control signal into a vibration motion of the shaker fixture on which each specimen is fixed. The entire device is shown in Figure 3.

The instrumentation of the bench and each specimen consists of the following (Fig. 3):

- An accelerometer PCB 333A30 fixed to the fixture at the head of the shaker which will serve to control the regulation of the closed loop. This accelerometer measures the input acceleration that should follow the reference acceleration (the imposed setpoint value).

- A fixed accelerometer Dytran 3225F3 at the beam end to directly record transmissibilities (acceleration ratio of response and excitation). This accelerometer weighs $0.6 \mathrm{~g}$ excluding its cable to minimize its influence on the structural response. 
- A strain gauge HBM 1LY15-1.5/350 fixed to the useful area of the specimen. The size of the grid is 1.5 by $1.2 \mathrm{~mm}$ in order to get more accurate measurements.

To determine the maximum acceleration supported by the shaker, it was necessary to know the moving mass of the system (Tab. 1). Thus, the maximum acceleration is $26.2 \mathrm{~g}$ knowing that the shaker achieves its maximum force at $650 \mathrm{~N}$.

Table 1. Masses (in kg) moved by the shaker.

\begin{tabular}{llll}
\hline Vibratory system & Clamping device & Specimen & Total \\
\hline 1.3 & 1 & 0.18 & 2.48 \\
\hline
\end{tabular}

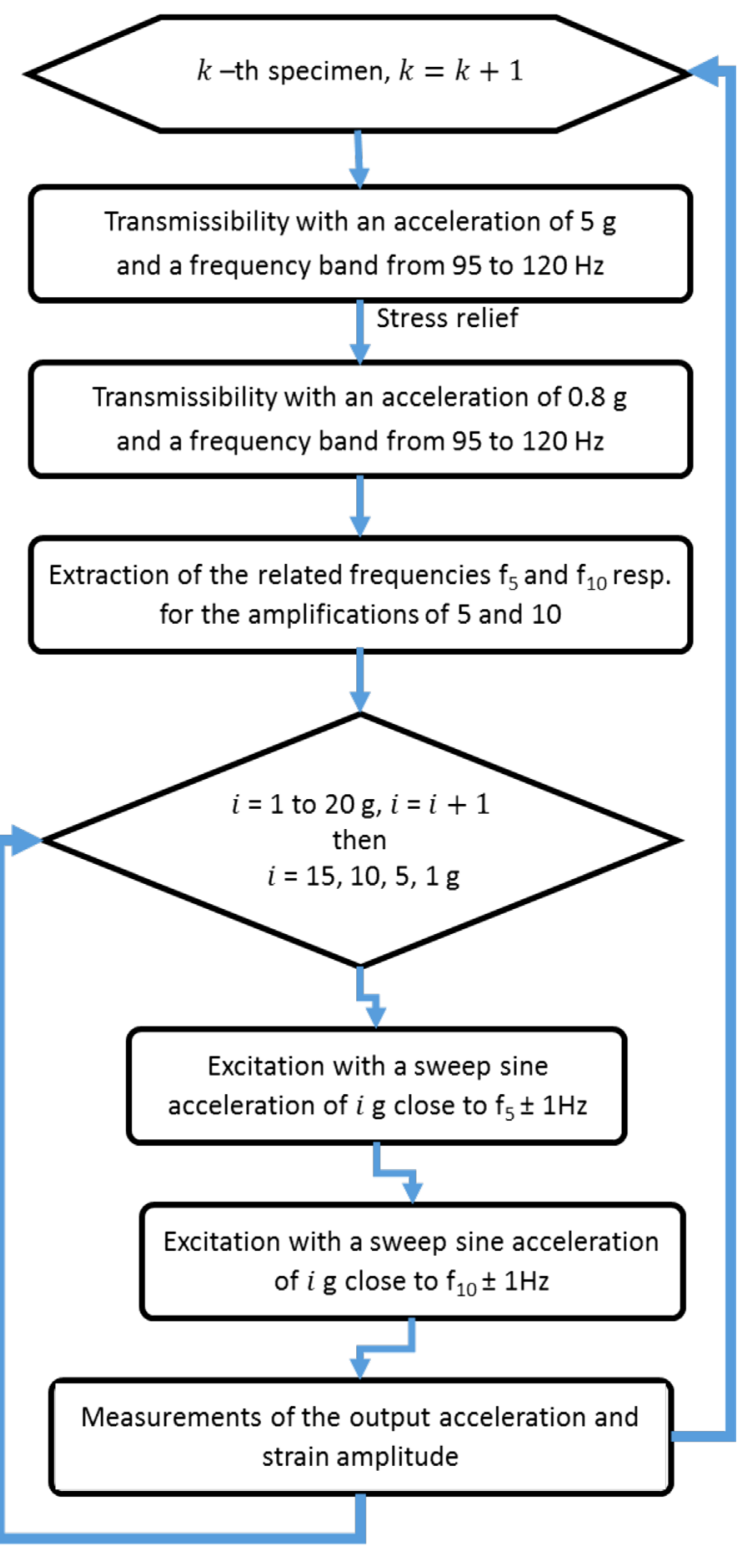

(a)

\subsection{Experimental procedure and data processing}

When a structure is excited at a frequency close to its resonance, a response amplification can be observed, which allows an amplification of the strain measurement on the specimen useful area. In this case, a phase shift is observed between the input and output signals. To study the linearity between the acceleration (input) and the specimen response (output) at different levels of amplification, we have considered two amplification levels: the first one at $5 \mathrm{~g} / \mathrm{g}$ and the second at $10 \mathrm{~g} / \mathrm{g}$. These amplification values were arbitrarily chosen before the resonance peak to keep the phase between the input and the output at less than $20^{\circ}$ [29]. As shown in Figure 4b,
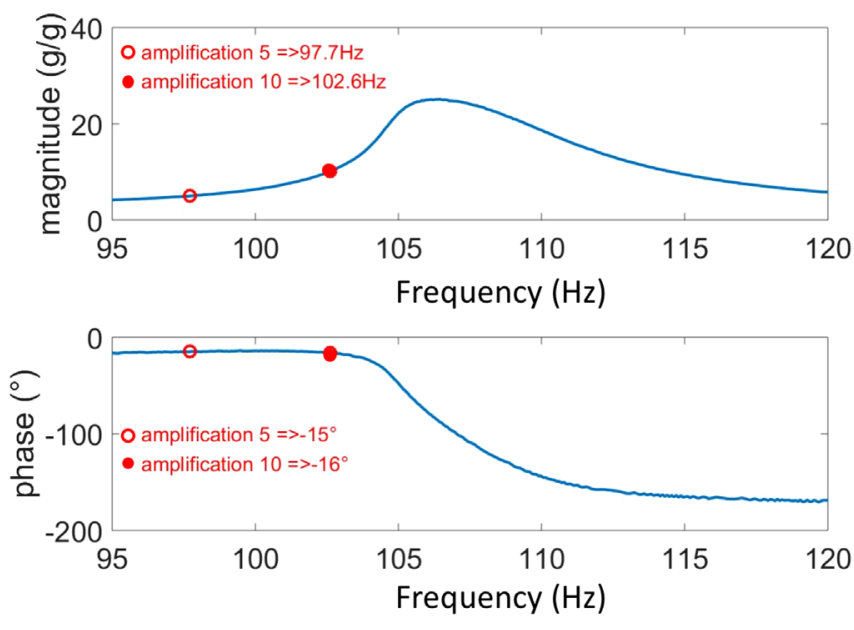

(b)

Fig. 4. (a) Flowchart of the experimental procedure and (b) example of a transmissibility obtained for $0.8 \mathrm{~g}$ excitation. 
these values were located on the transmissibility plateau to limit the variations of the related frequencies.

An L-shaped template was designed for ensuring the repetitive positioning of the specimens, the tightening being adjusted by means of a torque wrench.

The experimental procedure is described by the flowchart in Figure 4a:

Step 1. The test procedure began with a sweep sine at $5 \mathrm{~g}$. Without this first step, the linearity is not correct because we had found in a previous study that stress relief was observed when a structure was excited at high levels of acceleration [19,30].

Step 2. A second sweep sine was performed at $0.8 \mathrm{~g}$ over the frequency band from 95 to $120 \mathrm{~Hz}$. This interval contains the first resonance frequencies of the specimens. The sweep sine duration was $2 \mathrm{~min}$ (or $22.5 \mathrm{~Hz} / \mathrm{s}$ ). From the recorded transmissibility, the frequencies, denoted $f_{5}$ and $f_{10}$, related to the two selected amplifications were extracted. The acceleration value $(0.8 \mathrm{~g})$ was chosen in order to differentiate the sweep sines with magnitudes greater than $1 \mathrm{~g}$ and the transmissibilities. It has simplified the data postprocessing and it is easier to compare transmissibilities at the same acceleration level in order to detect if a change of material properties occurs.

Note. The ACP controller does not allow to excite a fixed frequency structure. Thus, to automate successive series of tests, each specimen was excited with a sweep sine over a very narrow frequency band $( \pm 1 \mathrm{~Hz})$, including the frequencies extracted per amplification considered. According to the example of Figure 4b, the amplifications of 5 and 10, respectively, give frequencies of 97.7 and $102.6 \mathrm{~Hz}$. The sweep sines are, respectively, performed from 96.6 to $98.7 \mathrm{~Hz}$ and from 101.6 to $103.6 \mathrm{~Hz}$.

The acceleration levels were arbitrarily chosen from 1 to $20 \mathrm{~g}$ with increasing steps of $1 \mathrm{~g}$. A decrease of acceleration levels was also considered in order to detect whether a change in the material behaviour has occurred. Only four levels are carried out $(15,10,5,1 \mathrm{~g})$. These sweeps were performed at small numbers of cycles (duration: 10 s, about 1,000 cycles) to avoid the fatigue phenomenon. The amplitude measures of each sensor are extracted from these data experiments. The same specimen was used for each test to avoid the change in test conditions. During this test phase, the time signals of the both accelerometers and the strain gauge were recorded continuously by an HBM quantum 840 A system. The sampling rate of the time signals was 1200 samples per second, which allows a good representation of each cycle. At the same time, the transmissibilities are calculated and saved by the ACP.

Step 4. Step 3 was repeated for the next excitation level or step 1 was performed on another specimen.
Figure 5 shows the time measurements of the three sensors during a complete test on the left and on the right, the associated focus on the $1 \mathrm{~g}$ acceleration level. The latter clearly shows the alternation of sweep sines at an amplification of 5 , then at 10 and the transmissibility (much more visible for the output acceleration and the strain).

Post-processing was carried out using Matlab ${ }^{\circledR}$. For each excitation level of Figure 5, the maximum and minimum per cycle with period $T_{i}$ were extracted to obtain all signal amplitudes such that:

$$
\begin{gathered}
X_{a}^{k}=\frac{\max _{t \in T_{i}}\left[X^{k}(t)\right]-\min _{t \in T_{i}}\left[X^{k}(t)\right]}{2} \\
(k=1 \text { to } 20 \text { or } k=15,10,5,1),
\end{gathered}
$$

where $X^{k}(t)$ corresponds to time acceleration or strain quantities and $X_{a}^{k}$ the related amplitudes per level denoted by $k$. These amplitudes were represented in Figure 6 for each specimen. The first part shows the ascendant levels corresponding to the increase of the acceleration levels. The second one shows the descendant levels corresponding to $15,10,5$ and $1 \mathrm{~g}$.

To obtain one point per level of excitation, the means of the amplitudes was calculated for each level and exhibited in Figure 7.

The efficiency of closed-loop regulation of the excitation signal was also checked from the amplitudes obtained from equation (1). Figure 8a gives the measures obtained by the accelerometer at the shaker fixture (input acceleration) according to each imposed acceleration level (reference excitation) for both amplifications (5 and 10). This figure allows checking that the input acceleration is equal to the reference excitation. Figure $8 \mathrm{~b}$ corresponding to the set of transmissibilities for one specimen shows the test repeatability. Despite the little variation observed around the resonance frequency, we can conclude that there is no change in the specimen behaviour during the test.

\section{Results of the experiment and discussion}

\subsection{Linearity}

We have tested five specimens by following the procedure described in Figure 4. The amplitudes of the output acceleration and the strain at each step were extracted for both amplifications. All these amplitudes are plotted in Figure 9 to exhibit the result dispersion. Although the specimens are manufactured using electrical discharge machining (wire-cut EDM), the dimensions vary slightly from one specimen to another. This has an impact on the modal response of the specimens and therefore has an impact on the dispersion observed in Figure 9.

We can see in Figure 9 that the linearity is perfect for the amplification of 5 , whereas the curves related to the amplification of 10 present a break in the slope and a plateau. Therefore, the amplification of 10 was not respected in our study from a certain acceleration level. The following sections provide some hypotheses to explain the trend observed for the amplification of 10 . 

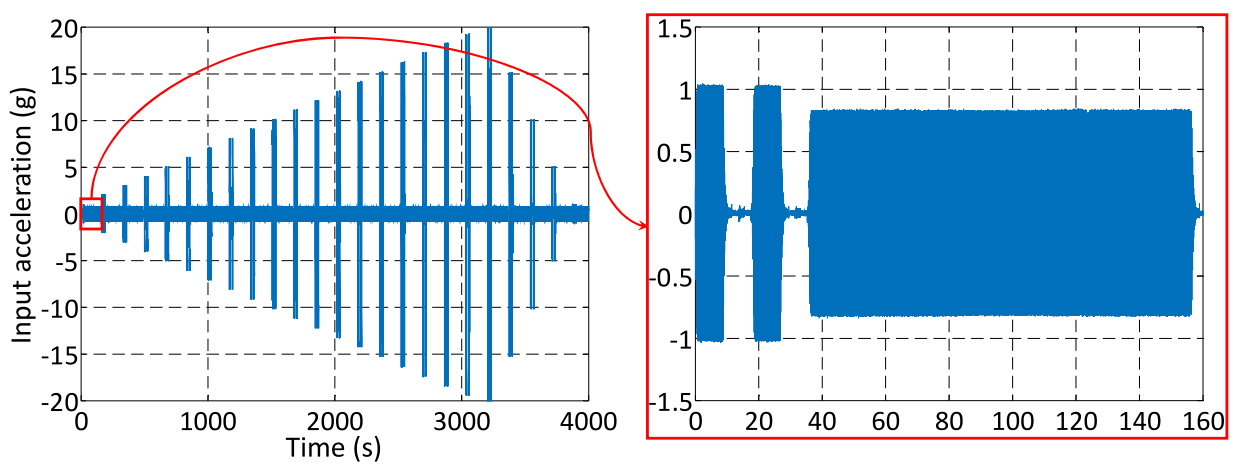

(a)
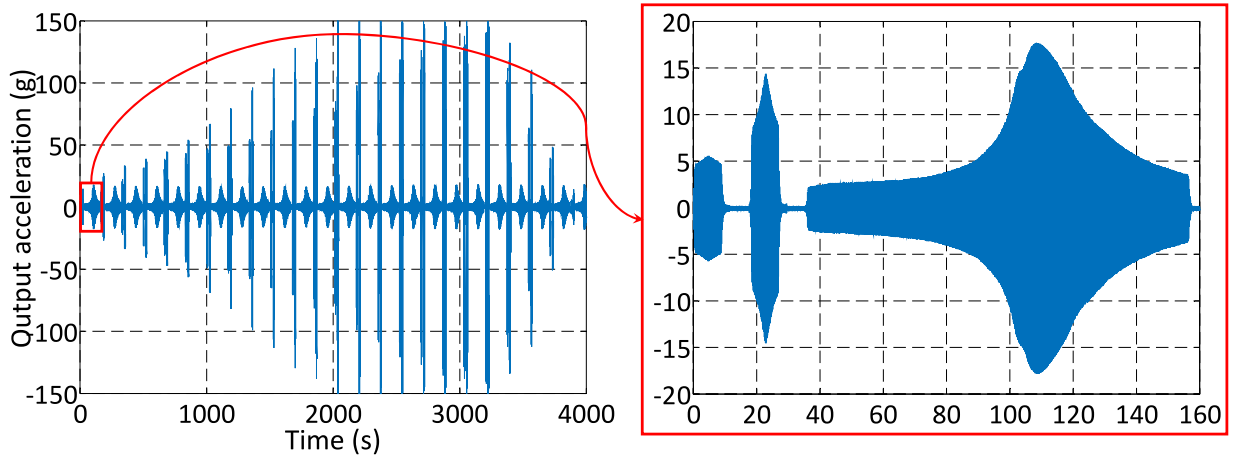

(b)
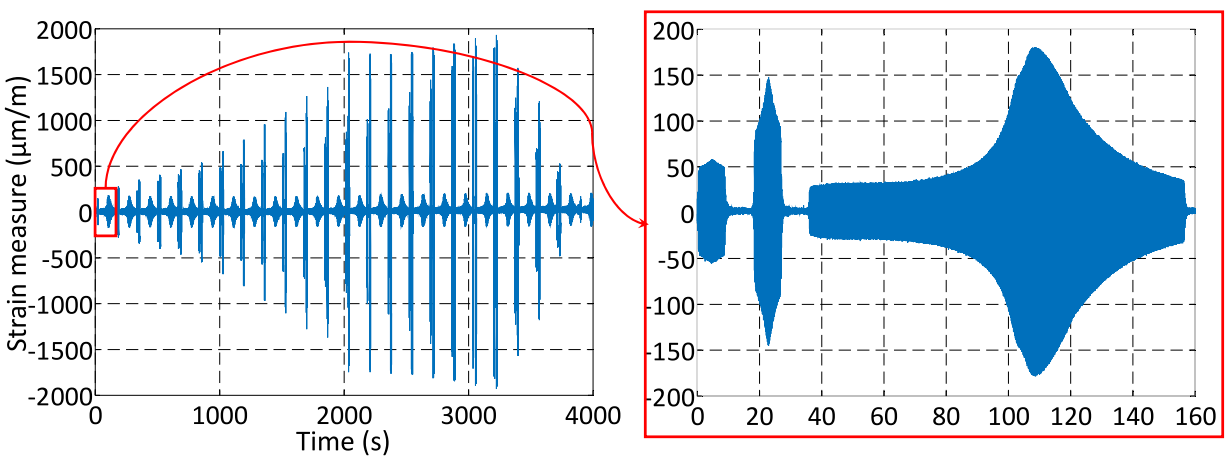

(c)

Fig. 5. Example of time signals for a complete test (on left), and a zoom on the $1 \mathrm{~g}$ level (on right) of the input acceleration (a), output acceleration (b) and strain (c).

\subsubsection{Irreversible strain}

Intuitively, the first hypothesis deals with the irreversible strain of the specimen. We had performed monotonic tensile tests at the maximum velocity of the used hydraulic machine in order to approach the strain rate obtained from the vibratory bench. The results presented in reference [19] have shown that the stresses reached always remained below the yield stress of the considered material. We have anticipated this hypothesis with the descendant stages $15,10,5$ and $1 \mathrm{~g}$ presented in Figure 4a. Figure 10 shows that the descendant stages are superimposed on the related ascendant stages. We can then conclude that the specimen does not undergo any irreversible structural strain. In addition, Figure 8b does not show a variation of the resonant frequency and damping, knowing that a stiffness loss has a non-negligible effect on the modal parameters [21-26].

\subsubsection{Influence of the assembly}

The vibration of the output accelerometer cable is inevitably accentuated during the tests because of the high excitation levels. The vibration cable generates dispersions in the response and has a non-negligible effect on the strain amplitude measures. We have then carried out tests with the glued cable to verify its significance. 


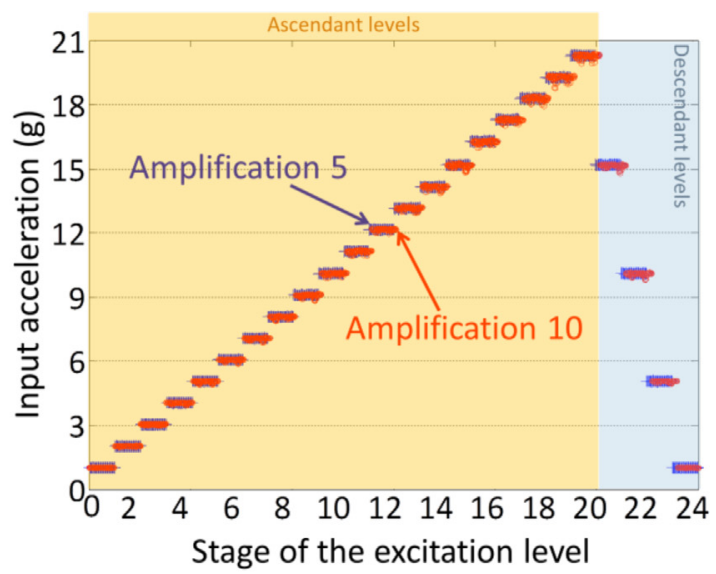

(a)

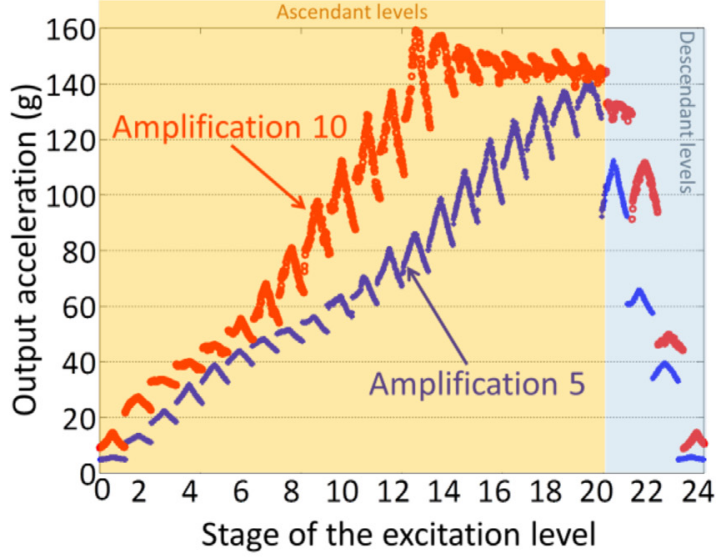

(b)

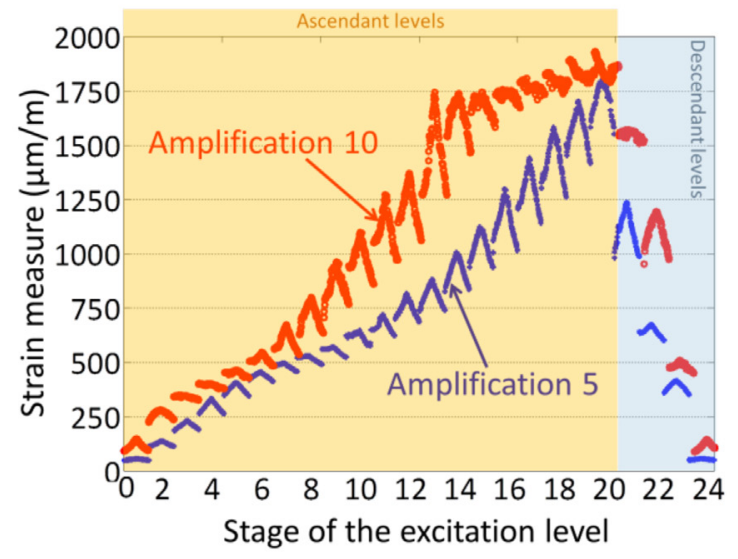

(c)

Fig. 6. Amplitudes of the input acceleration (a), output acceleration (b) and strain (c).

This test configuration cannot be adopted for the fatigue experiment as the cable increases the area rigidity, which may delay the failure. Figure 11 shows that the noise induced by the cable vibration is limited by the bonding and Figure 12 shows through, by another test, that the break in the slope is still present. It can be then concluded that the cable vibration is not responsible for the behaviour observed in Figure 9.

Another way has led us to investigate the effect of shaker misalignment. We therefore equipped the bench with a $3 \mathrm{D}$ accelerometer $(\mathrm{X} 1, \mathrm{Y}, \mathrm{Z})$ and a $1 \mathrm{D}$ accelerometer (X2). Figure 13a presents a schematic view of the shaker head and the accelerometer locations. A sweep sine was used as excitation on the frequency band from 95 to $120 \mathrm{~Hz}$. The measurements presented in Figure $13 \mathrm{~b}$ show that the imbalance is negligible. Indeed, X1 and X2 are of the same values, $\mathrm{Y}$ and $\mathrm{Z}$ are almost zero, so no misalignment of the shaker head is observed.

According to the literature, the break in slope is explained as follows:

- Too large deflection due to high level of excitation leading to geometrical nonlinearity [31];
- Damping of the complete system due to inertial forces and microscopic damages [32];

- Frictions in the clamp [33], which can result in an opening of the shaker fixture for high levels of excitation or micro-slips of the specimen in the fixture $[34,35]$.

\subsection{Delimitation of usable domains and simplification of instrumentation}

In order to guarantee the validity domains of a fatigue test, we chose to work only on the linear response domains. These domains were extracted from Figure 9a and Figure $9 \mathrm{~b}$ and represented in Figure 14 in considering the following:

- A linear regression passing through the origin of the axes;

- The straight lines are defined to obtain a slope coefficient close, respectively, to 5 or 10 for the amplifications 5 or 10;

- A linear regression coefficient $R^{2}$ close to 1 ;

- To have the largest linearity domain possible. 


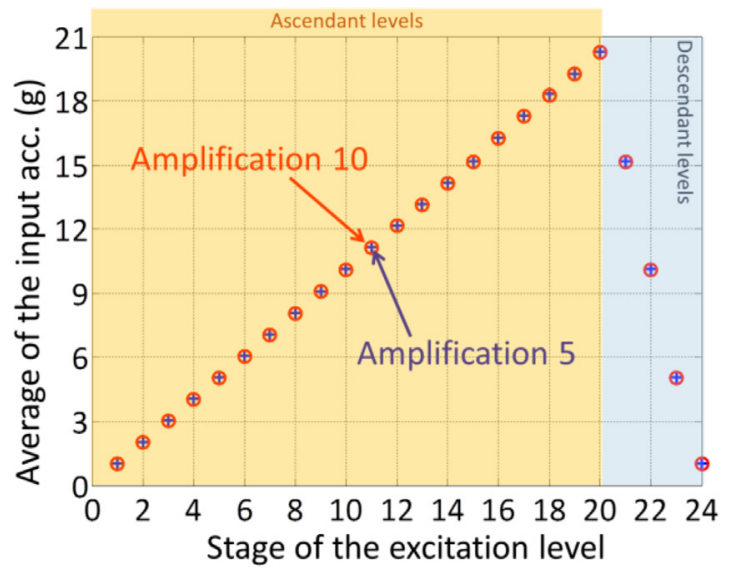

(a)

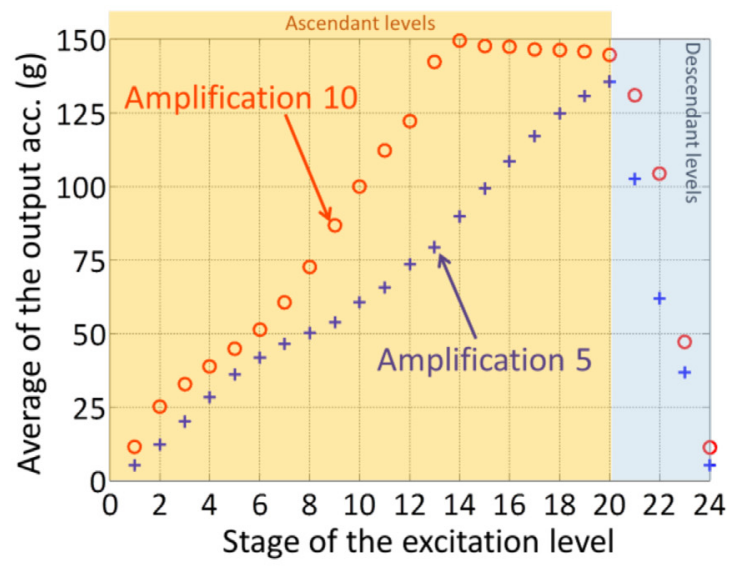

(b)

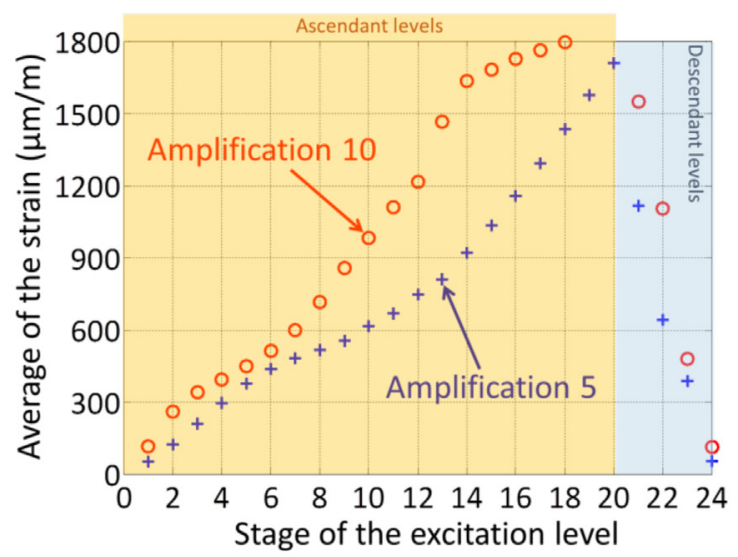

(c)

Fig. 7. Means calculated from Figure 6 of the input acceleration (a), output acceleration (b) and strain (c).
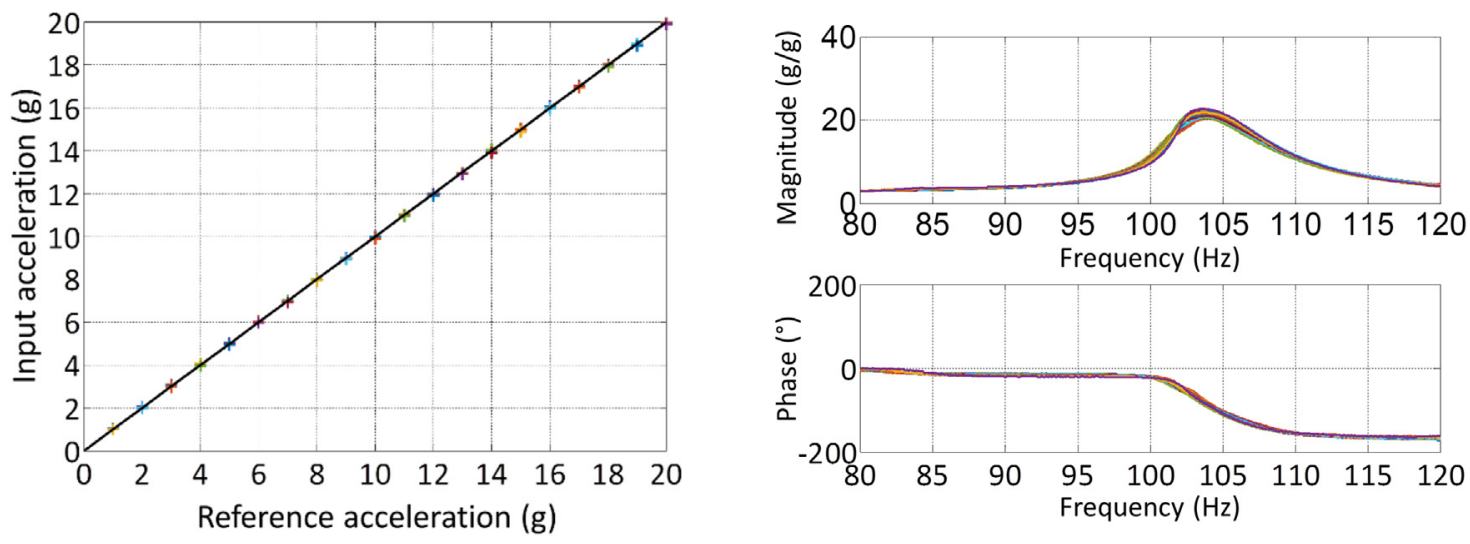

Fig. 8. (a) Control verification and (b) set of transmissibilities (in magnitude and phase).

The results are collected and shown in Table 2. The curve does not show a break in slope for the amplification 5 , the $(0-20 \mathrm{~g})$ excitation domain is then usable. For the amplification 10 , the domain is reduced to $(0-15 \mathrm{~g})$ due to the presence of the break in the slope. It can be deduced that the increase in amplification (leading to work on a frequency close to the resonant frequency) will have the consequence of reducing the linearity domain. Thanks to this study, we can consider simplifying the instrumentation so as not to disturb 


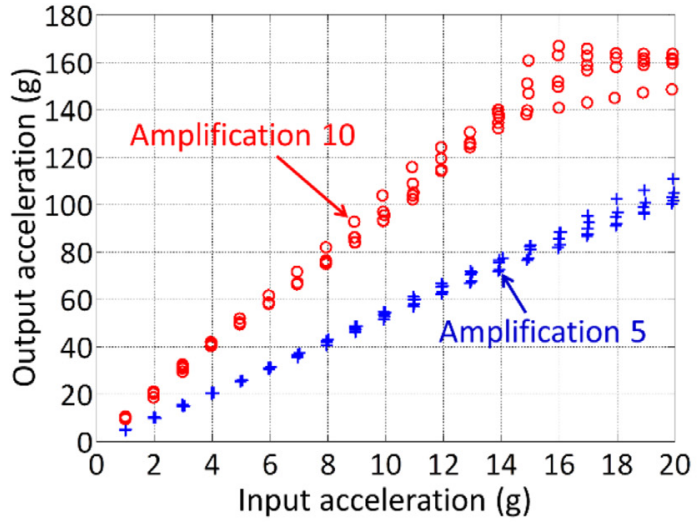

(a)

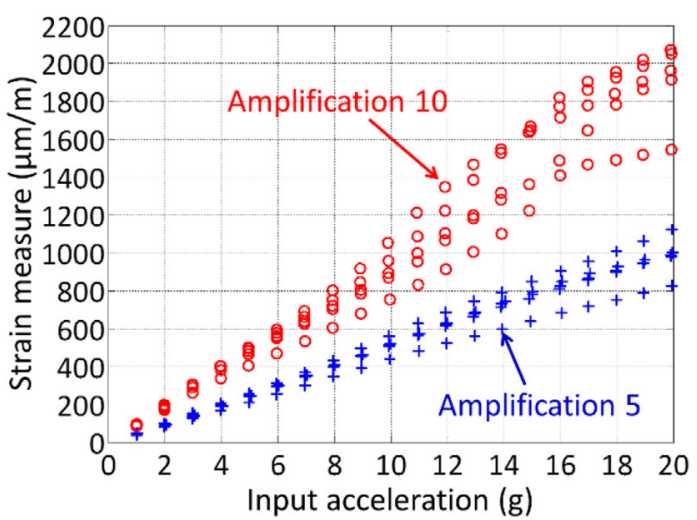

(b)

Fig. 9. Amplitude measures of the (a) beam response and (b) strain versus input accelerations.

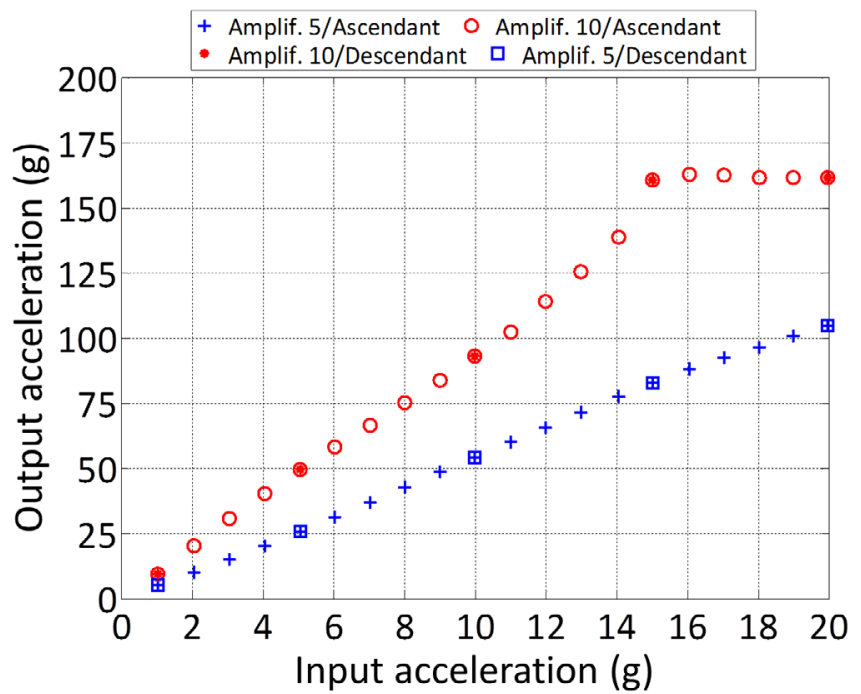

Fig. 10. Evolution of the input excitation level with the beam response. Example for one specimen.
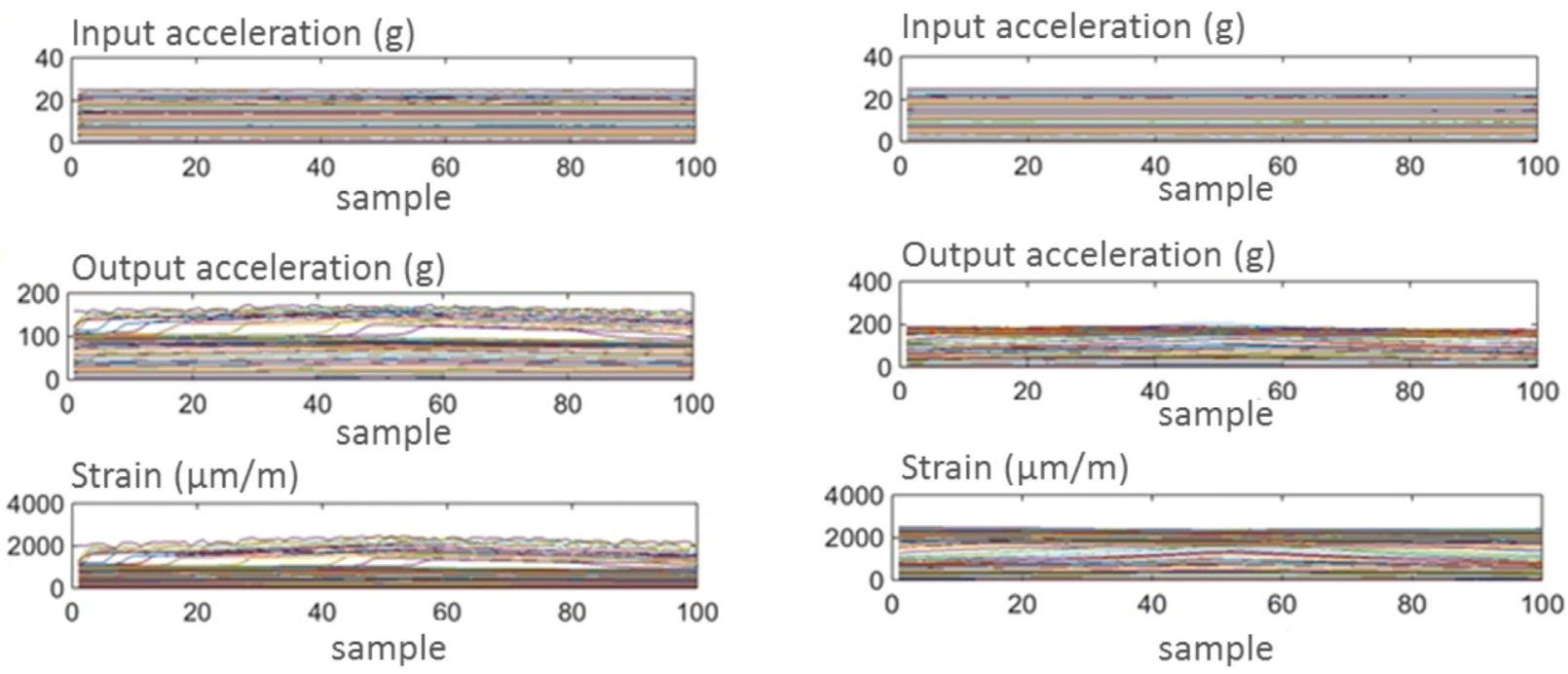

Fig. 11. Comparison between (a) not bonded and (b) bonded wire. 


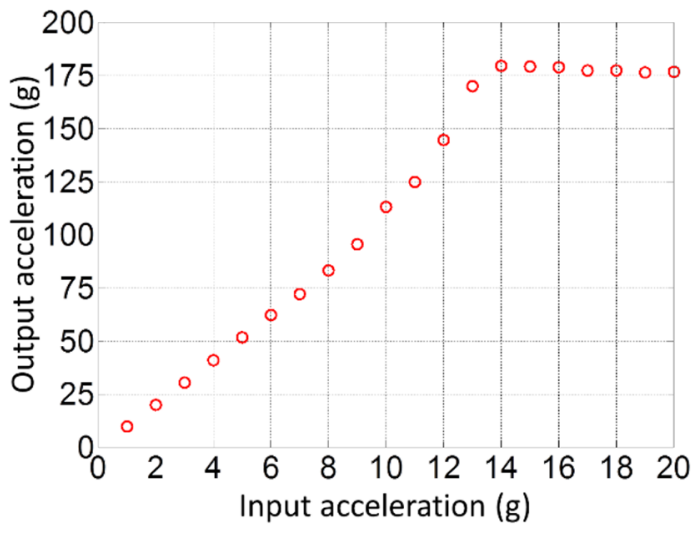

(a)

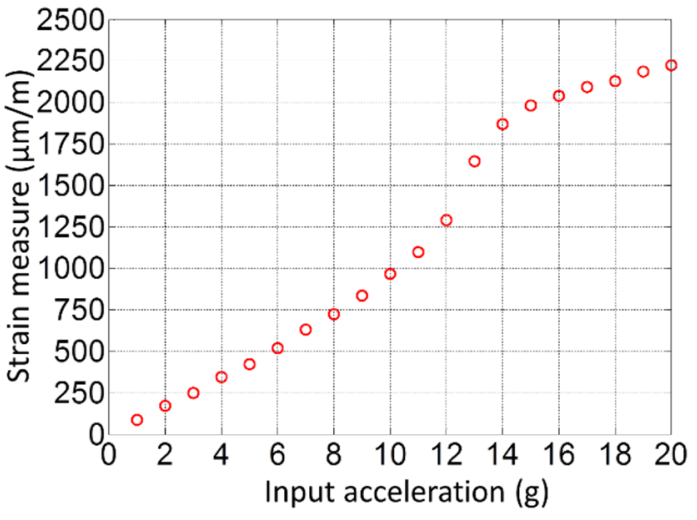

(b)

Fig. 12. Evolution of (a) output acceleration and (b) strain with the bonded wire for one specimen.

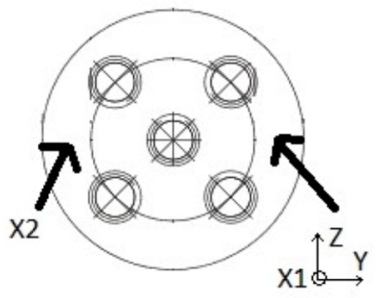

(a)
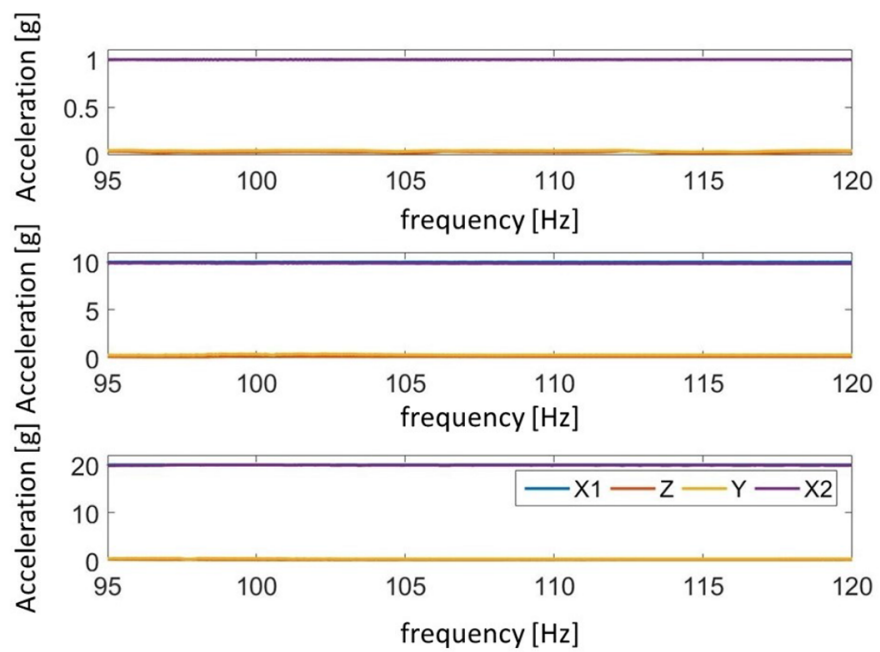

(b)

Fig. 13. (a) Schematic representation of the shaker head. (b) Acceleration measures with three levels of excitation (1, 10 and $20 \mathrm{~g}$ ).

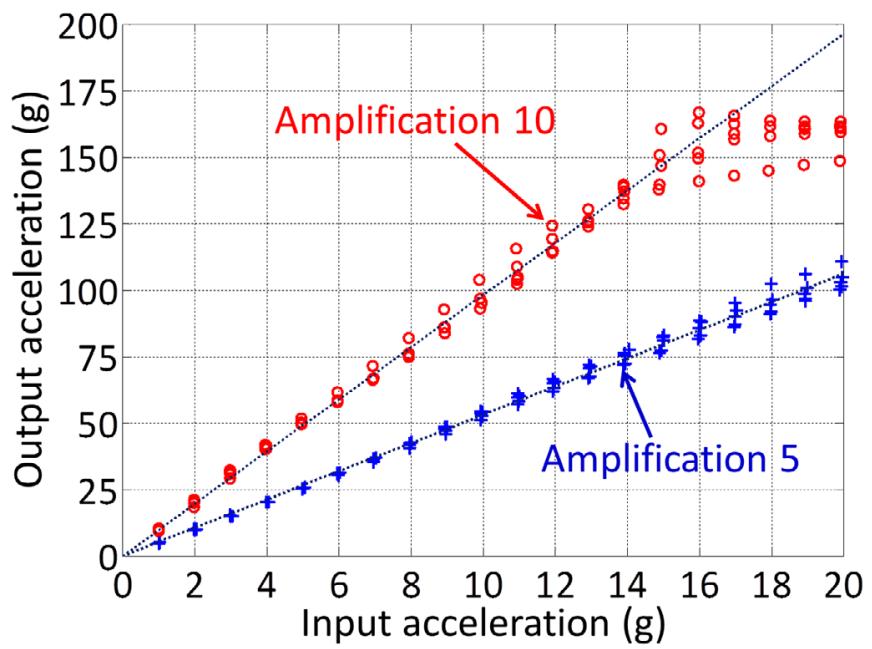

Fig. 14. Representation of extracted linear domains for both amplifications.
Table 2. Characteristics of the extracted linear domains.

\begin{tabular}{lll}
\hline Amplification & 5 & 10 \\
\hline Slope coefficient $(\mathrm{g} / \mathrm{g})$ & 5.31 & 9.82 \\
$R^{2}$ & 0.997 & 0.995 \\
Linear domains $(\mathrm{g})$ & $0-20$ & $0-15$ \\
\hline
\end{tabular}

the response of the structure by considering the following cases:

- The strain gauge fixed to the stress concentration raiser zone will tend to disturb the propagation of cracks due to the rigidity of the bonded area;

- The accelerometer adds mass to the structure and changes its response, but it is necessary for accessing to the transmissibilities. 


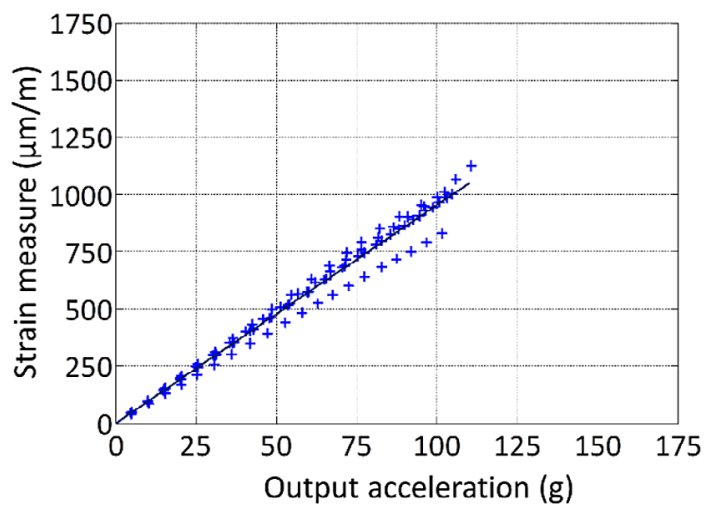

(a)

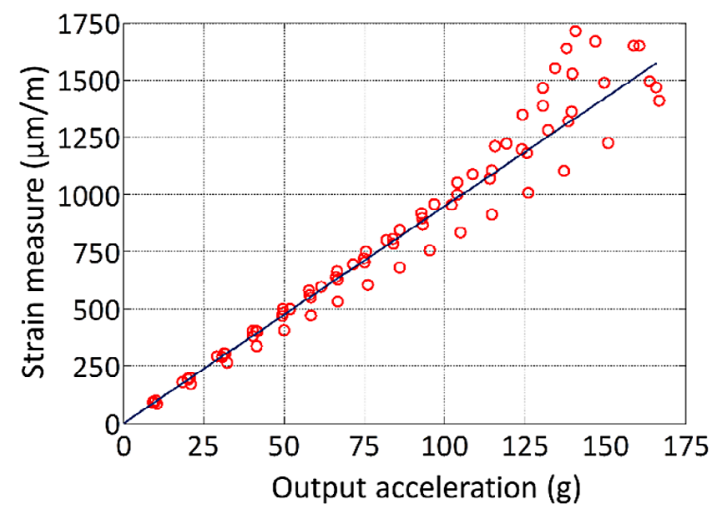

(b)

Fig. 15. Correlation between the specimen responses for amplifications (a) 5 and (b) 10 .

Table 3. Linearity parameters extracted from Figure 15.

\begin{tabular}{lll}
\hline Amplification & 5 & 10 \\
\hline Slope coefficient $(\mu \mathrm{m} / \mathrm{m} / \mathrm{g})$ & 9.55 & 9.49 \\
$R^{2}$ & 0.984 & 0.971 \\
\hline
\end{tabular}

The correlation between the accelerometer at the specimen end and the strain measurements is presented in Figure 15. We have only considered the experimental data included in the linear domains previously obtained (Fig. 14). The linear regression lines associated with both amplifications were plotted from these data.

The values are resumed in Table 3. The slope coefficients for both amplifications are close, which shows that the test frequency has no effect on the strain measurement. Therefore, we can consider removing the strain gauge in future tests, especially since the strain measurements obtained show a greater dispersion compared to the accelerometer measurements (Fig. 9).

\section{Conclusions}

In this study, we have carried out experimental tests to delimit the linearity domains of the system. These domains will be used for fatigue high-cycle vibratory tests using the bench. Thanks to this study, we have highlighted some difficulties of implementation, as a consequence of the test system choice.

It was possible to define linear response domains according to the excitation amplitude. The choice of amplification will be then a compromise between

- the levels of input acceleration and strain measures. The amplification of 5 corresponds to a test frequency lower than an amplification of 10 but the latter makes it possible to reach higher levels of strain;

- the phase difference between the input and output measurements. Effectively, the amplification of 5 will allow a negligible phase shift compared to the amplification of 10 . In addition, the amplification of 5 does not show a break in its slope and presents very little dispersion.

Acknowledgements. This study was conducted within the framework of the project MADNESS, which has been funded with the support from the European Union with the European Regional Development Fund (ERDF) and from the Regional Council of Normandie.

\section{References}

[1] U. Krupp, Fatigue crack propagation in metals and alloys: microstructural aspects and modelling concepts, John Wiley \& Sons, Inc., New York, 2007

[2] J.M. Morgan, W.W. Milligan, A $1 \mathrm{kHz}$ servohydraulic fatigue testing system, in: W.O. Soboyejo, T.S. Srivatsan (Eds.), Proceedings of the Conference on High Cycle Fatigue of Structural Materials, TMS, Warrendale, PA, 1997, pp. 305-312

[3] S. Stanzl-Tschegg, Very high cycle fatigue measuring techniques, Int. J. Fatigue 60 (2014) 2-17

[4] T.J. George, J. Seidt, M.-H. Herman Shen, T. Nicholas, C. Cross, Development of a novel vibration-based fatigue testing methodology, Int. J. Fatigue 26 (2004) 477-486

[5] A. Angeli, B. Cornelis, M. Troncossi, Synthesis of sine-onrandom vibration profiles for accelerated life tests based on fatigue damage spectrum equivalence, Mech. Syst. Signal Process. 103 (2018) 340-351

[6] A. Appert, C. Gautrelet, L. Khalij, R. Troian, Development of a test bench for vibratory fatigue experiments of a cantilever beam with an electrodynamic shaker, MATEC Web Conf. 165 (2018) 10007

[7] W.M. To, D.J. Ewins, A closed-loop model for single/multishaker modal testing, Mech. Syst. Signal Process. 5 (1991) 305-316

[8] H.M. Gomes, D. dos Santos Gaspareto, F. de Souza Ferreira, C.A.K. Thomas, A simple closed-loop active control of electrodynamic shakers by acceleration power spectral density for environmental vibration tests, Exp. Mech. 48 (2008) 683-692 
[9] M. Bennebach, H. Rognon, O. Bardou, Fatigue of structures in mechanical vibratory environment: from mission profiling to fatigue life prediction, Procedia Eng. 66 (2013) 508-521

[10] H. Hu, Y. Li, F. Zhao, Y. Miao, P. Xue, Q. Deng, Fatigue behavior of aluminium-stiffened plate subjected to random vibration loading, Trans. Nonferrous Metals Soc. China 24 (2014) 1331-1336

[11] M. Paulus, A. Dasgupta, E. Habtour, Life estimation model of a cantilevered beam subjected to complex random vibration, Fatigue Fract. Eng. Mater. Struct. 35 (2012) 1058-1070

[12] M. Mrsnik, J. Slavic, M. Boltezar, Frequency-domain methods for a vibration fatigue-life estimation: application to real data, Int. J. Fatigue 47 (2013) 8-17

[13] M. Cesnik, J. Slavic, M. Boltezar, Assessment of the fatigue parameters from random vibration testing: application to a rivet joint, Strojnivski vestnik J. Mech. Eng. 62 (2016) 471-482

[14] M. Mrsnik, J. Slavic, M. Boltezar, Multiaxial vibration fatigue - a theorical and experimental comparison, Mech. Syst. Signal Process. $76 / 77$ (2016) 409-423

[15] H. Rognon, T. Da Silva Botelhoa, I. Tawfiq, M. Bennebach, Fatigue sous environnement vibratoire: conception d'une éprouvette pour des essais accélérés en fatigue afin de valider une méthode de dimensionnement pour des structures réelles, Congrès Français de Mécanique, 2013

[16] D. Zanellati, D. Benasciutti, R. Tovo, Vibration fatigue tests by tri-axis shaker: design of an innovative system for uncoupled bending/torsion loading, Procedia Struct. Integr. 8 (2018) 92-101

[17] D. Zanellati, D. Benasciutti, R. Tovo, An innovative system for uncoupled bending/torsion tests by tri-axis shaker: numerical simulations and experimental results, MATEC Web Conf. 165 (2018) 16006

[18] G. Allegri, X. Zhang, On the inverse power laws for accelerated random fatigue testing, Int. J. Fatigue 30 (2008) 67-977

[19] L. Khalij, C. Gautrelet, A. Guillet, Fatigue curves of a lowcarbon steel obtained from vibrations experiments with an electrodynamic shaker, Mater. Des. 86 (2015) 640-648

[20] G. Murugan, K. Raghukandan, U.T.S. Pillai, B.C. Pai, K. Mahadevan, High cyclic fatigue characteristics of gravity cast AZ91 magnesium alloy subjected to transverse load, Mater. Des. 30 (2009) 2636-2641

[21] O.S. Salawu, Detection of structural damage through changes in frequency: a review, Eng. Struct. 19 (1997) 718-723
[22] S.M. McGuire, M.E. Fine, D. Achenbach, Crack detection by resonant frequency measurements, Metall. Mater. Trans. A 26 (1995) 1123-1127

[23] P. Lorenzino, A. Navarro, The variation of resonance frequency in fatigue tests as a tool for in-situ identification of crack initiation and propagation, and for the determination of cracked areas, Int. J. Fatigue 70 (2015) 374-382

[24] M. Colakoglu, K.L. Jerina, Material damping in 6061-T6511 aluminium to assess fatigue damage, Fatigue Fract. Eng. Mater. Struct. 26 (2003) 79-84

[25] F. Curà, A.E. Gallinatti, Fatigue damage identification by means of modal parameters, Procedia Eng. 10 (2011) $1697-1702$

[26] W. Xu, X. Yang, B. Zhong, Y. He, C. Tao, Failure criterion of titanium alloy irregular sheet specimens for vibrationbased bending fatigue testing, Eng. Fracture Mech. 195 (2018) 44-56

[27] C. Perruchet, P. Vimont, Résistance à la fatigue des matériaux en contraintes aléatoires, 1973

[28] Les traitements thermiques des aciers. Tba1050, Techniques de l'Ingénieur, 2004

[29] M. Cesnik, J. Slavic, M. Boltezar, Uninterrupted and accelerated vibrational fatigue testing with simultaneous monitoring of the natural frequency and damping, J. Sound Vib. 331 (2012) 5370-5382

[30] C.A. Walker, A.J. Waddell, D.J. Johnston, An investigation of the underlying processes, University of Strathclyde, Glasgow, SCT UK, 1994

[31] V.A. Jairazbhoya, P. Petukhovb, J. Quc, Large deflection of thin plates in cylindrical bending: non-unique solutions, Int. J. Solids Struct. 45 (2008) 3203-3218

[32] E. Habtour, D.P. Cole, J.C. Riddick, V. Weiss, M. Robeson, R. Sridharan, A. Dasgupta, Detection of fatigue damage precursor using a nonlinear vibration approach, Struct. Control Health Monitor. 23 (2016) 1442-1463

[33] M. Claeys, Réponses vibratoires non linéaires dans un contexte industriel: essais et simulations, $\mathrm{PhD}$ thesis, Ecole Centrale de Lyon, 2016

[34] L. Pesaresi, J. Armand, C.W. Schwingschackl, L. DSalles, C. Wong, An advanced underplaunder damper modeling approach based on a microslip contact model, in: ISROMAC, 2017

[35] H. Wentzel, M. Olsson, Mechanism of dissipation in frictional joints - influence of sharp contact edges and plastic deformation, Wear 265 (2008) 1814-1819

Cite this article as: C. Gautrelet, L. Khalij, A. Appert, R. Serra, Linearity investigation from a vibratory fatigue bench, Mechanics \& Industry 20, 101 (2019) 